\title{
Stereotactic radiosurgery in hemangioblastoma: Experience over 14 years
}

\author{
Nishant Goyal, Deepak Agrawal, Raghav Singla, Shashank Sharad Kale, Manmohan Singh, Bhawani Shankar Sharma \\ Department of Neurosurgery and Gamma Knife, All India Institute of Medical Sciences, New Delhi, India
}

\begin{abstract}
Background: Although gamma knife has been advocated for hemangioblastomas, it is not used widely by neurosurgeons. Objective: We review our experience over 14 years in an attempt to define the role of stereotactic radiosurgery (SRS) in the management of hemangioblastomas. Patients and Methods: A retrospective study was conducted on all patients of hemangioblastoma who underwent SRS at our institute over a period of 14 years (1998-2011). Gamma knife plans, clinical history, and radiology were reviewed for all patients. Results: A total of 2767 patients underwent gamma knife during the study period. Of these, $10(0.36 \%)$ patients were treated for 24 hemangioblastomas. Eight patients $(80 \%)$ had von Hippel-Lindau disease while two had sporadic hemangioblastomas. The median peripheral dose (50\% isodose) delivered to the tumors was $29.9 \mathrm{~Gy}$. Clinical and radiological follow-up data were available for eight patients. Of these, two were re-operated for persisting cerebellar symptoms. The remaining six patients were recurrence-free at a mean follow-up of 48 months (range 19-108 months). One patient had an increase in cyst volume along with a decrease in the size of the mural nodule. Conclusions: SRS should be the first option for asymptomatic hemangioblastomas. Despite the obvious advantages, gamma knife is not widely used as an option for hemangioblastomas.
\end{abstract}

Key words: Gamma knife radiosurgery, hemangioblastomas, stereotactic radiosurgery, von Hippel-Lindau syndrome

\section{Introduction}

Hemangioblastomas are benign, highly vascular tumors most frequently arising in the cerebellum, brainstem, or upper cervical cord. ${ }^{[1]}$ Nearly $75 \%$ of these lesions are sporadic. The remaining are seen in association with von Hippel-Lindau (VHL) disease, an inherited autosomal dominant disorder arising from mutation in the VHL tumor suppressor gene. ${ }^{[1]}$

Although, traditionally, surgical resection has been considered the treatment of choice for hemangioblastomas, ${ }^{[2]}$ all may not be amenable to complete surgical resection in

\section{Address for correspondence:}

Dr. Deepak Agrawal, Department of Neurosurgery and Gamma Knife, All India Institute of Medical Sciences,

New Delhi - 110 029, India.

E-mail: drdeepak@gmail.com

\begin{tabular}{|l|l|}
\hline \multicolumn{2}{|c|}{ Access this article online } \\
\hline Quick Response Code: & Website: \\
\hline & www.ruralneuropractice.com \\
\hline & \\
\hline
\end{tabular}

view of site, vascularity, and number. Furthermore, there is a significant risk of complications following surgery. As the natural history involves recurrence and onset of new lesions, surgery may be less suitable in some patients. Recently, stereotactic radiosurgery (SRS) has become an attractive alternative to surgery with encouraging results. ${ }^{[3-5]}$ We wish to report a series of 10 cases of hemangioblastomas treated by radiosurgery at our center over a 14-year period.

\section{Patients and Methods}

This retrospective study was conducted on all patients of hemangioblastoma who underwent SRS at our institute over the period of 14 years (1998-2011). Medical records and radiological studies of all the patients were reviewed to study the radiosurgical details and the clinicoradiological outcomes.

This is an open access article distributed under the terms of the Creative Commons Attribution-NonCommercial-ShareAlike 3.0 License, which allows others to remix, tweak, and build upon the work non-commercially, as long as the author is credited and the new creations are licensed under the identical terms.

For reprints contact: reprints@medknow.com

How to cite this article: Goyal N, Agrawal D, Singla R, Kale SS, Singh M, Sharma BS. Stereotactic radiosurgery in hemangioblastoma: Experience over 14 years. J Neurosci Rural Pract 2016;7:23-7. 


\section{Radiosurgery technique}

SRS was performed with Model B Leksell Gamma Knife (Elekta, Inc.). The procedure began with the application of a Leksell stereotactic frame with the patient under local scalp anesthesia. Following this, all patients underwent high-resolution magnetic resonance imaging (MRI), which was exported to a computer workstation via the hospital Ethernet for dose planning. In all patients, the target volume was defined as the enhancing tumor volume.

The mean volume of tumors was $1.635 \mathrm{~cm}^{3}$ (range from $1.8 \mathrm{~mm}^{3}$ to $7.6 \mathrm{~cm}^{3}$ ). Median dose to tumor was 29.9 Gy (20.1 Gy to $43.8 \mathrm{~Gy}$ ). The prescription isodose (50\% isodose) ranged from $14 \mathrm{~Gy}$ to $25 \mathrm{~Gy}$ with a median of $25 \mathrm{~Gy}$. All patients were given SRS in a single session [Table 1].

\section{Results}

Over the study period, 10 patients of hemangioblastoma (with a total of 27 lesions) underwent SRS at our institute. The mean age of the patients was 32.9 years, ranging from 20 to 44 years. Seven patients were males, and three were females. Out of the 10 patients, eight patients had VHL disease (80\%) while two patients had sporadic hemangioblastomas. Of the eight patients with VHL disease, five had multiple intracranial lesions, and other three had single intracranial lesions [Table 1]. The most common site of lesion was the cerebellum.

Seven patients had previously been operated for intracranial hemangioblastoma. One of these patients (patient number 5) was referred to us from a peripheral center when the surgery had to be aborted because the patient developed bradycardia intraoperatively. Of the three patients who underwent primary radiosurgery, two had multiple lesions, and the third opted for radiosurgery. Two patients had undergone ventriculoperitoneal (VP) shunt for raised intracranial pressure prior to radiosurgery (patient number 7 and 9). Clinically, most of the patients presented with cerebellar symptoms (five), followed by headache (three), myelopathy (two), and multiple cranial nerve involvement (one) [Table 1].

In this study, of a total of 27 lesions, 25 were intracranial, and two were located in the spinal cord. As our center lacks the facility of cyber-knife, the spinal lesions could not be managed by radiosurgery (patient number 3 and 4 ) and, therefore, underwent surgery. Our patient number 7 had six intracranial lesions including one lesion at the obex [Table 1]. This lesion at the obex was not treated by gamma knife to prevent damage to the brainstem. No acute side effects of radiation were seen in this study.

Six patients remained recurrence-free for a mean period of 48 months (range 19-108 months). Two (patient number 6 and 10) of these demonstrated radiological decrease in tumor volume [Figure 1]. In patient number 5 , the lesion disappeared completely over 4 years following gamma knife and had not recurred over the 9 years of follow-up. However, he developed a new lesion at the craniovertebral junction, which required surgery. Another patient (patient number 1) showed radiological evidence of decrease in mural nodule, but the cyst volume had increased. He was kept under close follow-up and was asymptomatic at the last follow-up at 40 months [Figure 2].

Table 1: Details of the patients who underwent SRS for hemangioblastoma

\begin{tabular}{|c|c|c|c|c|c|c|c|}
\hline $\begin{array}{l}\text { Patient } \\
\text { number }\end{array}$ & Age & Number of tumors & $\begin{array}{c}\text { Mean SRS } \\
\text { dose (in } \\
\text { Gy) }\end{array}$ & $\begin{array}{l}\text { Previous surgery } \\
\text { (number of times) }\end{array}$ & VHL & VP shunt & Follow-up \\
\hline 1 & $35 /$ male & 2 cranial & 36.05 & Yes (4) & Yes & No & $\begin{array}{l}\text { Reduction in size of mural nodule at } \\
40 \text { months. Increase in cyst volume }\end{array}$ \\
\hline 2 & 44/male & 1 cranial & 21.1 & Yes (1) & No & No & $\begin{array}{l}\text { Re-operated at } 5 \text { months for } \\
\text { persistent cerebellar symptoms }\end{array}$ \\
\hline 3 & 20/female & 1 cranial and 1 spinal & 25.2 & Yes (2) & Yes & No & $\begin{array}{l}\text { Re-operated at } 10 \text { months for } \\
\text { persistent cerebellar symptoms }\end{array}$ \\
\hline 4 & $32 /$ male & 6 cranial and 1 spinal & 30.01 & No & Yes & No & $\begin{array}{l}\text { Recurrence-free at last follow-up at } \\
19 \text { months, operated for spinal lesion }\end{array}$ \\
\hline 5 & $20 /$ male & $\begin{array}{l}1 \text { cranial, developed } \\
\text { one later at CVJ }\end{array}$ & 20.8 & Yes (1) & Yes & No & $\begin{array}{l}\text { Follow-up at } 9 \text { years. Lesion } \\
\text { disappeared } 4 \text { years following GKT }\end{array}$ \\
\hline 6 & $34 /$ male & 4 cranial & 29.55 & No & Yes & No & $\begin{array}{l}\text { Reduction in size at } 3 \text { years. } \\
\text { Asymptomatic radiation necrosis }\end{array}$ \\
\hline 7 & $31 /$ male & 6 cranial ( 5 treated) & 34.52 & Yes (3) & Yes & Yes & Lost to follow-up \\
\hline 8 & 39/female & 1 cranial & 20.1 & Refused & Yes & No & Lost to follow-up \\
\hline 9 & $30 /$ male & 2 cranial & 26.2 & Yes (2) & Yes & Yes & Recurrence-free at 27 months \\
\hline 10 & 44/female & 1 cranial & 40.5 & Yes (1) & No & No & Reduction in size at 56 months \\
\hline
\end{tabular}

SRS: Stereotactic radiosurgery, VHL: Von Hippel-Lindau, VP: Ventriculoperitoneal, CVJ: Craniovertebral junction, GKT: Gamma knife therapy 


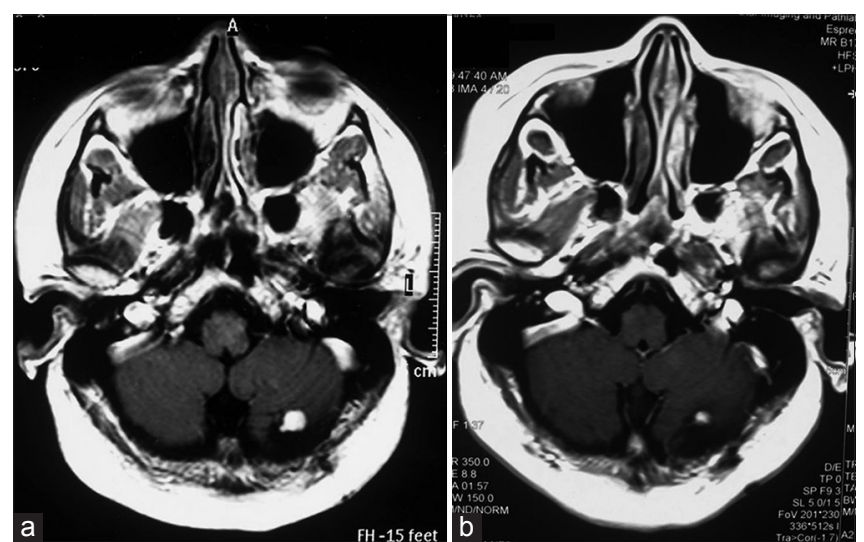

Figure 1: Axial gadolinium-enhanced magnetic resonance images of patient number 10 showing mural nodule with a small cyst (a). 1 year after radiosurgery, there was a significant decrease in the size of the mural nodule (b)

Two patients (patient number 2 and 3) who had large cystic lesions responsible for the cerebellar symptoms persisted to be symptomatic even after radiosurgery. These patients underwent surgery at 5 months and 10 months, respectively. Two patients were lost to follow-up.

\section{Discussion}

Hemangioblastomas are highly vascular, well-circumscribed, benign tumors of the central nervous system. ${ }^{[1]}$ They comprise only about $1-2.5 \%$ of all cranial tumors and $7-12 \%$ of posterior fossa tumors. ${ }^{[6,7]}$ They are composed of stromal cells, abundant capillaries, pericytes, and mast cells and categorized as WHO grade I tumors of uncertain origin.

Radiologically, ${ }^{[8]}$ cerebellar hemangioblastomas are traditionally described to have four types. Type 1 , accounting for $5 \%$ of posterior fossa hemangioblastomas, is a simple cyst without a macroscopic nodule. Type 2 is a cyst with a mural nodule and accounts for $60 \%$ of posterior fossa hemangioblastomas. Type 3 is solid tumors without a cystic component (26\%), and type 4 is solid tumors with small internal cysts (9\%).

Hemangioblastomas most frequently affect young adults. Nearly $20 \%$ are associated with VHL syndrome. ${ }^{[9]}$ In this study, the age ranged from 20 to 44 years (mean - 32.9 years). Eight of the patients $(80 \%)$ in our study had VHL disease. The higher proportion may be explained due to multicentricity of lesions in this group of patients and, therefore, a higher likelihood of them undergoing radiosurgery.

The presenting features depend on the location of the lesion and may be headache, cerebellar signs, and
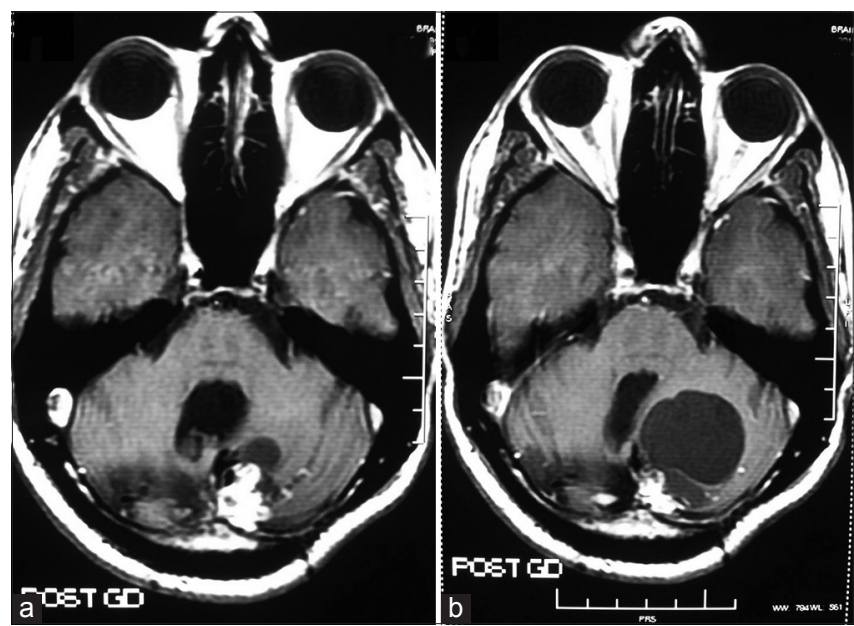

Figure 2: Axial gadolinium-enhanced magnetic resonance images of patient number 1 showing mural nodule with a small cyst (a). 1 year after radiosurgery, there was a decrease in the size of the mural nodule with increase in the cyst size (b) causing significant compression on the fourth ventricle

nystagmus. Symptoms are usually slowly progressive giving time to the treating physician to individualize the treatment modality. Surgical resection has traditionally been considered the treatment of choice for hemangioblastomas. ${ }^{[2]}$

Sub-total resection of hemangioblastoma invariably leads to recurrence. Conway et al. report a $20 \%$ recurrence rate of hemangioblastomas following surgical resection. ${ }^{[10]}$ Classically, hemangioblastomas have a small, well-delineated, vascular mural nodule making them susceptible to radiosurgery. Radiosurgery is a noninvasive, day care procedure where multiple lesions may be treated in the same sitting with satisfactory tumor control.

A review of literature shows encouraging results using radiosurgery for hemangioblastomas. Moss et al. reported actuarial control rates of $84 \%$ and $81 \%$ at 3 and 5 years, respectively, in 64 lesions with at least 2 years of follow-up. ${ }^{[5]}$ In their review of 67 cases, Matsunaga et al. described a tumor control rate of $83.6 \%$ over a mean period of 63 months. ${ }^{[4]}$ Tago et al. reported a $96 \%$ control rate at 10 years in 13 patients with 46 hemangioblastomas. ${ }^{[11]}$

However, as SRS treats only the solid component of the tumor, it may not be a good treatment option in a patient with mass effect secondary to a cystic component. Moreover, studies have demonstrated that radiation can at least transiently induce increases in vascular permeability, leading to peritumoral edema, and cyst formation. ${ }^{[12-14]}$ In their study of 11 hemangioblastomas, Niemelä et al. reported that surgical evacuation of the 
cyst was done after radiosurgery in three of five cystic hemangioblastomas. ${ }^{[15]}$ Tago et al. reported five lesions undergoing increase in cyst volume after radiosurgery with one necessitating surgery to resect the cystic mass. ${ }^{[1]}$ Pan et al. suggested that although SRS was good for hyper vascular tumors, it was not effective for cystic tumors. ${ }^{[16]}$ Of their 13 patients undergoing SRS, two developed cyst expansion requiring surgery. A more recent study by Moss et al. reported six such lesions treated with surgical drainage and resection $<3$ months after SRS because of symptomatic cyst growth. ${ }^{[5]}$ They hypothesize cessation of fluid collection occurring nearly 1 year after SRS.

In our series, two patients (patient number 2 and 3) who had type 2 hemangioblastomas with large cystic lesions responsible for the cerebellar symptoms persisted to be symptomatic even after radiosurgery. These patients underwent surgery at 5 months and 10 months, respectively. In retrospect, the authors feel that cyst aspiration followed by SRS might have been better treatment options for these two patients. Kano et al. propose a similar management protocol for large cystic hemangioblastomas. ${ }^{[3]}$ The authors feel that type 3,4 , and selective cases of type 2 hemangioblastomas are better candidates for SRS.

In general, SRS serves as a new modality for treatment in unresectable lesions, multiple tumors, recurrent cases, and in cases with subtotal resection. Seven of our patients were recurrent cases. Six had multiple intracranial lesions. The indications for the use of SRS in hemangioblastomas are not well-defined. Kano et al. advise SRS in cases of unresectable tumors with mass effect (may be preceded by stereotactic cyst aspiration) and after incomplete resection in resectable tumors. ${ }^{[3]}$ Moss et al. advocate SRS in asymptomatic hemangioblastomas of size $<3 \mathrm{~cm} \cdot{ }^{[5]}$ According to them, for asymptomatic lesions in VHL, SRS is indicated if the size is more than $5 \mathrm{~mm}$, and the lesion shows a cystic component or radiological progression. ${ }^{[5]}$ In their study, Tago et al. observed that small lesions with high-dose respond better to SRS ${ }^{[11]}$ Kano et al. reported a better prognosis in cases with solid tumor, tumor volume $<3.2 \mathrm{ml}$, and marginal dose $>15 \mathrm{~Gy}^{[3]}$ In our series, the higher marginal dose (median of $25 \mathrm{~Gy}$ ) might explain why in three of our cases, there was a reduction in the size of the mural nodule, and none of other lesions showed an increase in the nodule's size. The authors believe that gamma knife should be considered the first-line of management for lesions $<3 \mathrm{~cm}$ in maximum diameter without significant mass effect.
Hemangioblastomas are slow-growing tumors exhibiting a saltatory growth pattern. The absence of growth seen at follow-up may simply be a period of quiescence. Therefore, it may be difficult to comment with conviction whether the local tumor control rate in an absence of decrease in size can actually be attributed to SRS. Yamamoto et al. argued that the absence of growth would not mean treatment unless significant growth was seen in tumor before radiosurgery. ${ }^{[17]}$ Hence, long-term follow-up is required before any survival benefit may be attributed to SRS.

Tago et al. had recurrence outside the SRS-treated area in five of their 13 patients. ${ }^{[11]}$ Kano et al. reported new lesions outside the irradiated area in 10 of their 32 patients. ${ }^{[3]}$ In our study, one patient (patient number 5) developed a new lesion at the cranio-vertebral junction, which was outside the irradiated area [Table 1]. At our institute, follow-up MRI is done 6 months after radiosurgery and then yearly for the first 5 years.

In our study, two patients had undergone VP shunt for raised intracranial pressure prior to SRS. Page et al. reported symptomatic radiation necrosis requiring $\mathrm{VP}$ shunt and corticosteroid therapy in one of their patients. ${ }^{[18]}$

A major concern of SRS is radiation toxicity. It may be a significant problem in cases with multiple lesions with overlapping radiation fields. Moss et al. reported 11 tumors in their series with radiation necrosis. ${ }^{[5]}$ In our series, radiosurgery was deferred for a lesion at the obex in one of the patients (patient number 7) to avoid radiation toxicity to brainstem [Table 1]. Another patient (patient number 6) showed asymptomatic radiation necrosis [Table 1].

\section{Conclusion}

SRS appears to be a suitable modality of treatment for hemangioblastomas in certain conditions, especially unresectable, recurrent, multiple, and subtotally resected tumors. This study demonstrates that SRS is an effective method for local control of hemangioblastomas. However, cases with a cystic component might show an increase in the size of the cyst and, therefore, need to be monitored closely.

\section{Financial support and sponsorship \\ Nil.}

\section{Conflicts of interest}

There are no conflicts of interest. 


\section{References}

1. Resche F, Moisan JP, Mantoura J, de Kersaint-Gilly A, Andre MJ, Perrin-Resche I, et al. Haemangioblastoma, haemangioblastomatosis, and von Hippel-Lindau disease. Adv Tech Stand Neurosurg 1993;20:197-304.

2. Rengachary SS. Haemangioblastoma. In: Wilkins RH, Rengachary SS, editors. Neurosurgery. New York: McGraw-Hill; 1985. p. 772-82.

3. Kano H, Niranjan A, Mongia S, Kondziolka D, Flickinger JC, Lunsford LD. The role of stereotactic radiosurgery for intracranial hemangioblastomas. Neurosurgery 2008;63:443-50.

4. Matsunaga S, Shuto T, Inomori S, Fujino H, Yamamoto I. Gamma knife radiosurgery for intracranial haemangioblastomas. Acta Neurochir (Wien) 2007;149:1007-13.

5. Moss JM, Choi CY, AdlerJR Jr, Soltys SG, Gibbs IC, Chang SD. Stereotactic radiosurgical treatment of cranial and spinal hemangioblastomas. Neurosurgery 2009;65:79-85.

6. Jeffreys R. Clinical and surgical aspects of posterior fossa haemangioblastomata. J Neurol Neurosurg Psychiatry 1975;38:105-11.

7. Neumann HP, Eggert HR, Weigel K, Friedburg H, Wiestler OD, Schollmeyer P. Hemangioblastomas of the central nervous system. A 10-year study with special reference to von Hippel-Lindau syndrome. J Neurosurg 1989;70:24-30.

8. Lee SR, Sanches J, Mark AS, Dillon WP, Norman D, Newton TH. Posterior fossa hemangioblastomas: MR imaging. Radiology 1989;171:463-8.

9. Neumann HP, Berger DP, Sigmund G, Blum U, Schmidt D, Parmer RJ, et al. Pheochromocytomas, multiple endocrine neoplasia type 2, and von Hippel-Lindau disease. N Engl J Med 1993;329:1531-8.

10. Conway JE, Chou D, Clatterbuck RE, Brem H, Long DM, Rigamonti D.
Hemangioblastomas of the central nervous system in von Hippel-Lindau syndrome and sporadic disease. Neurosurgery 2001;48:55-62.

11. Tago M, Terahara A, Shin M, Maruyama K, Kurita H, Nakagawa K, et al. Gammaknife surgery for hemangioblastomas.J Neurosurg 2005;102Suppl: 171-4.

12. Cao Y, Tsien CI, Shen Z, Tatro DS, Ten Haken R, Kessler ML, et al. Use of magnetic resonance imaging to assess blood-brain/blood-glioma barrier opening during conformal radiotherapy. J Clin Oncol 2005;23:4127-36.

13. Qin D, Ou G, Mo H, Song Y, Kang G, Hu Y, et al. Improved efficacy of chemotherapy for glioblastoma by radiation-induced opening of blood-brain barrier: Clinical results. Int J Radiat Oncol Biol Phys 2001;51:959-62.

14. Shuto T, Inomori S, Fujino H, Nagano H, Hasegawa N, Kakuta Y. Cyst formation following gamma knife surgery for intracranial meningioma. J Neurosurg 2005;102 Suppl: 134-9.

15. Niemelä M, Lim YJ, Söderman M, Jääskeläinen J, Lindquist C. Gamma knife radiosurgery in 11 hemangioblastomas. J Neurosurg 1996;85:591-6.

16. Pan L, Wang EM, Wang BJ, Zhou LF, Zhang N, Cai PW, et al. Gamma knife radiosurgery for hemangioblastomas. Stereotact Funct Neurosurg 1998;70 Suppl 1:179-86.

17. Yamamoto M, Ide M, Umebara Y, Hagiwara S, Jimbo M, Takakura K. Gamma knife radiosurgery for brain tumors: Postirradiation volume changes compared with preradiosurgical growth fractions. Neurol Med Chir (Tokyo) 1996;36:358-63.

18. Page KA, Wayson K, Steinberg GK, Adler JR Jr. Stereotaxic radiosurgical ablation: An alternative treatment for recurrent and multifocal hemangioblastomas. A report of four cases. Surg Neurol 1993;40:424-8.

\section{New features on the journal's website}

\section{Optimized content for mobile and hand-held devices}

HTML pages have been optimized of mobile and other hand-held devices (such as iPad, Kindle, iPod) for faster browsing speed.

Click on [Mobile Full text] from Table of Contents page.

This is simple HTML version for faster download on mobiles (if viewed on desktop, it will be automatically redirected to full HTML version)

\section{E-Pub for hand-held devices}

EPUB is an open e-book standard recommended by The International Digital Publishing Forum which is designed for reflowable content i.e. the text display can be optimized for a particular display device.

Click on [EPub] from Table of Contents page.

There are various e-Pub readers such as for Windows: Digital Editions, OS X: Calibre/Bookworm, iPhone/iPod Touch/iPad: Stanza, and Linux: Calibre/Bookworm.

\section{E-Book for desktop}

One can also see the entire issue as printed here in a 'flip book' version on desktops.

Links are available from Current Issue as well as Archives pages.

Click on View as eBook 